\title{
Relato de um caso de neutropenia congênita grave em um lactente jovem
}

\author{
A case report of severe congenital neutropenia in a young infant
}

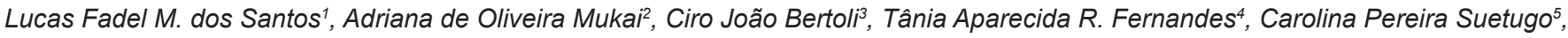 \\ Livia Fadel M. dos Santos ${ }^{5}$
}

\section{RESUMO}

Objetivo: Relatar um caso de neutropenia congênita grave e alertar os pediatras sobre tal diagnóstico em pacientes jovens, com infecções recorrentes.

Descrição do caso: Lactente jovem com 45 dias de vida, com história de febre alta, letargia, recusa alimentar e hemogramas repetidos com leucopenia importante à custa de polimorfonucleares. A hipótese diagnóstica foi confirmada pelo aspirado de medula óssea, que mostrou hipoplasia de série granulocítica e completa ausência de neutrófilos maduros. Foi introduzida antibioticoterapia de largo espectro e estimulador da formação de colônias de granulócitos. O paciente evoluiu para óbito em decorrência de complicações infecciosas após 21 dias de internação.

Comentários: Trata-se de um lactente jovem, portador de uma rara desordem congênita que leva à intensa neutropenia, deixando-o vulnerável a infecções graves e potencialmente fatais. À internação, o paciente apresentava sinais e sintomas sugestivos de sepse, sendo introduzido antibioticoterapia de amplo espectro, necessária por se tratar de lactente jovem, neutropênico e febril. A hipótese diagnóstica se baseou na história clínica e nos leucogramas alterados, sendo posteriormente confirmada pelo aspirado de medula óssea. Foi introduzido o estimulador da formação de colônias de granulócitos, que geralmente é efetivo, porém, nesse caso, não houve sucesso e o paciente evoluiu para óbito devido à grave infecção.

Palavras-chave: neutropenia congênita; elastase de leucócito; fator estimulador de colônias de granulócitos.

\section{ABSTRACT}

Objective: To report a case of severe congenital neutropenia and alert pediatricians about its diagnosis in young patients with recurrent infectious diseases.

Case description: Young infant with 45 days of life, with a history of high fever, lethargy, poor feeding and repeated blood counts showing significant leucopenia due to a significant decrease of polymorphonuclear cells. The diagnosis was confirmed by bone marrow aspirate showing hypoplasia of the granulocytic series and complete absence of mature neutrophils. Treatment was started with broad-spectrum antibiotic therapy and granulocyte colony-stimulating factor, but the patient died due to infectious complications 21 days after hospital admission.

Comments: This is a young infant with a rare congenital disorder that leads to severe neutropenia and, therefore, susceptible to potentially fatal infections. In the hospital the infant showed signs and symptoms of sepsis. The diag-
Instituição: Hospital Universitário de Taubaté da Universidade de Taubaté (Unitau), Taubaté, SP, Brasil

${ }^{1}$ Residência Médica em Pediatria pela Unitau; Médico-residente de Medicina Intensiva Pediátrica da Universidade Federal de São Paulo (Unifesp), São Paulo, SP, Brasil

${ }^{2}$ Mestre em Ciências pela Faculdade de Medicina da Universidade de São Paulo (USP); Professora Assistente da Disciplina de Pediatria da Unitau; Chefe da Unidade de Terapia Intensiva Pediátrica do Hospital Universitário de Taubaté da Unitau, Taubaté, SP, Brasil

${ }^{3}$ Doutor em Medicina pela Faculdade de Medicina da USP; Professor Assistente Doutor da Disciplina de Pediatria da Unitau; Chefe do Serviço de Pediatria do Hospital Universitário de Taubaté da Unitau, Taubaté, SP, Brasil

${ }^{4}$ Doutoranda em Medicina pela Universidade Estadual de Campinas (Unicamp); Professora Assistente da Disciplina de Clínica Médica-Hematologia da Unitau, Taubaté, SP, Brasil

${ }^{5}$ Acadêmica de Medicina da Unitau, Taubaté, SP, Brasil
Endereço para correspondência:

Lucas Fadel M. dos Santos

Rua Dr. Emilio Winther, 620, apto. 53, bloco B - Jardim das Nações

CEP 12030-000 - Taubaté/SP

Email: lucasfadel@yahoo.com.br

Recebido em: 1/10/2010

Aprovado em: 2/2/2011

Conflito de interesse: nada a declarar. 
nosis was based on the clinical history and the presence of repeated altered white cell counts and it was confirmed by bone marrow aspirate. Granulocyte colony-stimulating factor is generally effective, but, in this case, the patient died with a severe infection.

Key-words: congenital neutropenia; leukocyte elastase; granulocyte colony-stimulating factor.

\section{Introdução}

A neutropenia congênita grave (NCG) foi descrita pela primeira vez em 1956 por Rolf Kostmann como uma doença de herança autossômica recessiva em membros de uma família sueca com pais consanguíneos ${ }^{(1)}$. Estes apresentavam contagem de neutrófilos menor do que $0,5 \times 10^{9} / \mathrm{L}$ e, consequentemente, infecções bacterianas recorrentes com risco de vida, desde os primeiros meses de vida ${ }^{(1,2)}$. O aspirado de medula óssea de tais pacientes demonstrava precursores de neutrófilos, nos estágios de maturação de promielócitos e mielócitos, em geral com núcleo atípico, vacuolização do citoplasma e tendência à apoptose celular ${ }^{(3)}$. Além disso, foi observada completa ausência de neutrófilos maduros ${ }^{(1,4)}$.

Trata-se de uma rara desordem (1 a 2 por milhão), que geralmente se manifesta com infecções bacterianas recorrentes desde os primeiros meses de vida, devido à intensa diminuição na contagem de neutrófilos, geralmente menores que $200 / \mathrm{mm}^{3(5)}$. Hoje, sabe-se que a doença possui diferentes formas de herança genética ${ }^{(6)}$, podendo ser autossômica dominante (mais comum), autossômica recessiva (síndrome de Kostmann clássica), recessiva ligada ao X e esporádica. Todas as formas têm evolução clínica semelhante, com diferença provável no gene que sofre mutação. As mutações genéticas conhecidas são ELA2, mais comum na forma autossômica dominante, e HAX1, na recessiva. Ambas não são exclusivas nem obrigatórias em nenhuma das formas de herança, podendo ainda aparecer em conjunto ${ }^{(5,7,8)}$.

Em geral os pacientes apresentam abscessos cutâneos, aftas orais, infecções de vias aéreas superiores e inferiores, e diarreia de forma recorrente já no primeiro ano de vida. A sobrevida depende da gravidade das doenças infecciosas e da resposta ao tratamento com fator estimulador de colônias de granulócitos (G-CSF), que, na maioria dos casos, é positiva e melhora muito a qualidade de vida desses pacientes ${ }^{(9,10)}$. Na ausência de resposta ao G-CSF, a única opção é o transplante de medula óssea ${ }^{(5)}$. A maior longevidade dos pacientes tratados com o G-CSF trouxe à tona a possibilidade de novas complicações, como o surgimento de mielodisplasia e leucemia mieloide aguda ${ }^{(5,7)}$, por resposta anormal das células progenitoras ao G-CSF${ }^{(10,11)}$.

O objetivo do presente estudo foi relatar a apresentação clínica e a evolução de um paciente com NCG, descrever a fisiopatologia da doença, os métodos diagnósticos, a terapêutica e as perspectivas futuras. O paciente foi acompanhado diariamente durante o período em que esteve na Unidade de Terapia Intensiva Pediátrica do Hospital Universitário de Taubaté, sendo enfatizada as evoluções clínica e laboratorial após a introdução do tratamento.

\section{Relato de caso}

Paciente 45 dias de vida, sexo masculino, transferido para o Hospital Universitário de Taubaté com quadro de febre, letargia, hipotonia, vômitos, recusa alimentar e diarreia há dois dias. No exame físico de entrada encontrava-se em regular estado geral, hipoativo, reativo, mucosas úmidas e descoradas, afebril $\left(\mathrm{t}=36,7^{\circ} \mathrm{C}\right)$, anictérico e acianótico, peso $3450 \mathrm{~g}$, comprimento $53 \mathrm{~cm}$, frequência cardíaca de $147 \mathrm{bpm}$, frequência respiratória de 46rpm. Não foram encontradas anormalidades na oroscopia, na inspeção de pele, anexos e fâneros e, também, não havia linfonodos palpáveis. O exame do tórax não evidenciava retrações ou abaulamento, a expansibilidade era simétrica, o murmúrio vesicular presente bilateralmente sem ruídos adventícios. À ausculta cardíaca, observou-se ritmo regular em dois tempos, bulhas normofonéticas e ausência de sopro audível. Também não foram encontradas anormalidades na palpação e na inspeção do precórdio, bem como qualquer alteração na inspeção e palpação abdominal. Os membros e as extremidades também não apresentavam alterações. A genitália era tipicamente masculina, os testículos tópicos, com discreta hiperemia na região perineal, nas virilhas e raízes de coxa.

Os hemogramas realizados no hospital de origem evidenciavam contagem total de leucócitos sempre inferior a 400 células, sem contagem diferencial e sem alterações na série vermelha e nas plaquetas. $\mathrm{Na}$ entrada, foi solicitado novo hemograma que apresentou 600 leucócitos, com $16 \%$ de neutrófilos, $3 \%$ de eosinófilos, $58 \%$ de linfócitos e $23 \%$ de monócitos, demonstrando claramente uma leucopenia à custa de polimorfonucleares. De relevante, apresentava ainda proteína C-reativa de $283,2 \mathrm{mg} / \mathrm{dL}$. Não foi isolado nenhum agente em hemocultura.

Após estabilização, foi introduzida a antibioticoterapia de largo espectro, com vancomicina e cefepime. Em seguida, foi solicitado aspirado de medula óssea, que evidenciou 
hipoplasia de série granulocítica acentuada, com parada na maturação e consequente ausência de neutrófilos maduros; apresentava também sinais de transformação megaloblástica leve, diagnosticando-se, assim, a presença de NCG.

$\mathrm{Na}$ terapêutica, introduziu-se o G-CSF, na dose de $10 \mathrm{ug} / \mathrm{kg} / \mathrm{dia}$. A medicação a princípio mostrou-se eficiente ao elevar a contagem de leucócitos para $1.200 / \mathrm{mm}^{3}$. Posteriormente, observou-se nova queda no número de leucócitos e não houve resposta mesmo com dose mais altas de 20,50 e $75 \mathrm{ug} / \mathrm{kg} / \mathrm{dia}$, introduzidas após 10,13 e 16 dias de tratamento, respectivamente. A Tabela 1 mostra a evolução dos hemogramas do paciente. Do ponto de vista clínico, o paciente apresentou quadro de choque séptico, com insuficiência respiratória e renal, culminando com o óbito aos 66 dias de vida.

\section{Discussão}

A NCG é uma rara desordem multigênica, com diferentes graus de hereditariedade ${ }^{(6)}$. A maioria dos casos é representada pela forma autossômica dominante, seguida pela forma clássica autossômica recessiva denominada Síndrome de Kostmann $^{(1,2)}$. Mais raramente, apresentam-se sob formas esporádicas e também ligadas ao cromossomo $\mathrm{X}^{(7,8)}$.

A fisiopatologia ainda não está totalmente esclarecida. Estudos do início da década atual mostraram que 50 a $60 \%$ dos pacientes portadores da forma autossômica tinham mutações no gene ELA2, responsável por codificar a enzima elastase neutrofílica ${ }^{(12,13)}$. O papel da EN ainda é obscuro; uma possibilidade seria de que a EN anômala no retículo endoplasmático induziria à formação de uma proteína alterada que provocaria a interrupção na maturação e a indução da apoptose celular ${ }^{(14,15)}$. Outra possibilidade seria uma supressão do LEF-1 (fator potencializador de transcrição e ligação linfoide), que é, pelo menos em parte, responsável pela expressão da ELA2 ${ }^{(16)}$, já que foi encontrada diminuição importante da elastase neutrofílica em pacientes com neutropenia congênita, independentemente da presença ou não de mutações na ELA2 ${ }^{(5)}$. Novos estudos são necessários para esclarecer qual o real papel da mutação na ELA2 na patogênese da NCG. Recentemente, foram demonstradas mutações na proteína HAX1 em pacientes portadores da síndrome de Kostmann. HAX1 é uma molécula da membrana mitocondrial que controla sua permeabilidade e detém funções antiapoptóticas. A proteína alterada levaria à morte celular precoce, porém os reais mecanismos ainda permanecem obscuros ${ }^{(17)}$. Existe ainda uma parcela considerável de pacientes negativos tanto para a mutação ELA2 quanto para a $\mathrm{HAX}^{(7,8)}$, sugerindo que existem outras mutações responsáveis pela NCG não identificadas.

Clinicamente, a doença se apresenta sob forma de infecções recorrentes desde os primeiros meses de vida, sem qualquer distinção fenotípica entre as diferentes formas de hereditariedade. Tais infecções possuem gravidade variável, desde abcessos cutâneos, gengivite, periodontite e úlceras orais até infecções graves e potencialmente fatais, que requerem antibioticoterapia de largo espectro ${ }^{(4)}$. Os germes mais comumente envolvidos são: Staphylococcus aureus, Pseudomonas aeuruginosa e Escherichia coli(18). Descrevem-se, ainda, sintomas neurológicos (epilepsia e retardo mental) em pacientes

Tabela 1 - Evolução dos hemogramas durante a internação e após introdução de G-SCF

\begin{tabular}{|c|c|c|c|c|c|c|c|}
\hline $\begin{array}{c}\text { Dias } \\
\text { de vida }\end{array}$ & $\begin{array}{c}\mathrm{Hb} \\
\text { (g/dL)/Ht (\%) }\end{array}$ & $\begin{array}{c}\text { Leucócitos } \\
\text { por } \mathrm{mm}^{3}\end{array}$ & $\begin{array}{l}\text { Neutrófilos } \\
\text { por } \mathrm{mm}^{3}\end{array}$ & $\begin{array}{l}\text { Linfócitos } \\
\text { por } \mathrm{mm}^{3}\end{array}$ & $\begin{array}{l}\text { Monócitos } \\
\text { por } \mathrm{mm}^{3}\end{array}$ & $\begin{array}{l}\text { Plaquetas } \\
\text { por } \mathrm{mm}^{3}\end{array}$ & Evento \\
\hline 45 & & 400 & & & & & \\
\hline 46 & & 600 & 91 & 318 & 138 & & Inícin C CSE \\
\hline Internação & & 600 & 94 & 348 & 138 & & InIClO do G-CSF \\
\hline 48 & $11,0 / 31$ & 700 & & & & 94.000 & \\
\hline 50 & $9,4 / 28$ & 800 & & & & 180.00 & \\
\hline 52 & $9,5 / 28$ & 1.200 & 144 & 1020 & 60 & 156.00 & \\
\hline 54 & $10,3 / 31$ & 600 & & & & & \\
\hline 55 & $10,0 / 30$ & 600 & & & & & $\uparrow G-C S F(20 u g / k g / d i a)$ \\
\hline 58 & $10,2 / 29$ & 800 & & & & 87.000 & $\uparrow$ G-CSF (50ug/kg/dia) \\
\hline 60 & $8,9 / 26$ & 500 & & & & 97.000 & \\
\hline 61 & $6,2 / 19$ & 500 & & & & 85.000 & $\uparrow$ G-CSF (75ug/kg $/ \mathrm{dia})$ \\
\hline 64 & $6,0 / 19$ & 900 & & & & 90.000 & \\
\hline 65 & $7,6 / 22$ & 700 & & & & 60.000 & \\
\hline
\end{tabular}

G-CSF: Estimulador de Formação de Colônias de Granulócitos. 
portadores de uma segunda mutação na proteína HAX1, expressa principalmente no sistema nervoso central ${ }^{(19)}$.

A suspeita diagnóstica é baseada em leucogramas que, repetidamente, demonstram contagem de neutrófilos inferior a $0,5 \times 10^{9} / \mathrm{L}$, associada à história de infecções bacterianas recorrentes. A confirmação é feita pelo aspirado de medula óssea, com ausência de neutrófilos maduros e maturação interrompida, principalmente na fase de promielócitos ${ }^{(4)}$.

Em 1987, foi descrito pela primeira vez o tratamento com G-CSF, capaz de elevar e manter a contagem de neutrófilos acima de $1 \times 10 \% / \mathrm{L}$ em $80 \%$ dos casos, o que aumentou a sobrevida e a qualidade de vida de tais pacientes. A dose terapêutica varia entre 1 a $120 \mathrm{ug} / \mathrm{kg} / \mathrm{dia}$, porém raramente são necessárias doses superiores $25 \mathrm{ug} / \mathrm{kg} / \mathrm{dia}^{(20,21)}$. Estudos posteriores demonstraram que o G-CSF garante alguma proteção contra a apoptose espontânea dos leucócitos ${ }^{(22,23)}$. Nos pacientes refratários a tal droga, a única opção terapêutica é o transplante de medula óssea com célula tronco.

A longevidade desses pacientes aumentou o risco do desenvolvimento de síndrome mielodisplásica e leucemia mieloide aguda (MA). Tais complicações estão relacionadas, em 80\% dos casos, com mutações adquiridas no gene que codifica os receptores do $\mathrm{G}-\mathrm{CSF}^{(24,25)}$, denominado $\mathrm{CSF} 3 \mathrm{R}^{(26,27)}$. O risco médio de desenvolver LMA é de $21 \%$ em dez anos. Pacientes menos responsivos apresentam elevação em $40 \%$ no risco de desenvolverem LMA em dez anos, versus $11 \%$ naqueles mais responsivos ao fator estimulador de colônia ${ }^{(28)}$. O desenvolvimento de LMA ou de mielodisplasia impossibilita prosseguir o tratamento com G-CSF, restando como única alternativa o transplante de medula óssea ${ }^{(26)}$.

Desde 1994, o Severe Chronic Neutropenia International Registry (SCNIR) registra todos os casos de NCG. Até hoje, foram registrados aproximadamente 700 pacientes acompanhados em sua evolução e tratamento. Todas as falhas terapêuticas e complicações também são devidamente monitoradas ${ }^{(8)}$.

No caso descrito, a hipótese diagnóstica foi levantada pelo quadro clínico e leucogramas, sendo posteriormente confirmada pelo aspirado de medula óssea, não havendo boa resposta terapêutica, mesmo com doses elevadas de G-CSF. A presença de anemia e de plaquetopenia foi provável complicação decorrente da infecção e das punções repetidas. O quadro séptico grave não pode ser descartado como um dos possíveis limitadores ao aumento do número de leucócitos.

Estudos complementares são necessários a fim de desvendar como as mutações descritas levam à interrupção da maturação dos neutrófilos na fase de promielócitos e, possivelmente, descobrir novos genes responsáveis pela fisiopatologia da NCG, Com isso, talvez, seja possível desenvolver novas estratégias terapêuticas mais efetivas e com menor risco de efeitos colaterais.

\section{Referências bibliográficas}

1. Kostmann R. Infantile genetic agranulocytosis; agranulocytosis infantilis hereditaria. Acta Paediatr 1956;45 (Suppl 105):1-78.

2. Kostmann R. Infantile genetic agranulocytosis: a review with presentation of ten new cases. Acta Paediatr Scand 1975;64:362-8.

3. Williams GT, Smith CA, Spooncer E, Dexter TM, Taylor DR. Haemopoietic colony stimulating factors promote cell survival by suppressing apoptosis. Nature 1990;343:76-9.

4. Welte K, Zeidler C, Dale DC. Severe congenital neutropenia. Semin Hematol 2006;43:189-95.

5. Mamishi S, Esfahani AS, Parvaneh N, Diestelhorst J, Rezaei N. Severe congenital neutropenia in 2 siblings of consanguineous parents. The Role of HAX1 Deficiency. J Investing Allergol Clin Immunol 2009;19:500-3.

6. Boztug K, Welte K, Zeidler C, Klein C. Congenital neutropenia syndromes. Immunol Allergy Clin North Am 2008;28:259-75.

7. Ward AC, Dale DC. Genetic and molecular diagnosis of severe congenital neutropenia. Curr Opin Hematol 2009;16:9-13.

8. Zeidler C, Germeshausen M, Klein C, Welte K. Clinical implications of ELA2, HAX1, and G-CSF-receptor (CSF3R) mutations in severe congenital neutropenia. Br J Haematol 2008;144:459-67.

9. Zeidler C, Boxer L, Dale DC, Freedman MH, Kinsey S, Welte K. Management of Kostmann syndrome in the G-CSF era. Br J Haematol 2000;109:490-5.

10. Carlsson G, Aprikyan AA, Tehranchi R, Dale DC, Porwit A, Hellström-Lindberg $\mathrm{E}$ et al. Kostmann syndrome: severe congenital neutropenia associated with defective expression of $\mathrm{Bcl}-2$, constitutive mitochondrial release of

cytochrome c, and excessive apoptosis of myeloid progenitor cells. Blood 2004;103:3355-61.

11. Kobayashi M, Yumiba C, Kawaguchi Y, Tanaka Y, Ueda K, Komazawa $Y$ et al. Abnormal responses of myeloid progenitor cells to recombinant human colony-stimulating factors in congenital neutropenia. Blood 1990;75:2143-9.

12. Horwitz MS, Duan Z, Korkmaz B, Lee HH, Mealiffe ME, Salipante SJ. Neutrophil elastase in cyclic and severe congenital neutropenia. Blood 2007;109:1817-24.

13. Horwitz M, Benson KF, Person RE, Aprikyan AG, Dale DC. Mutations in ELA2, encoding neutrophil elastase, define a 21- day biological clock in cyclic haematopoiesis. Nat Genet 1999;23:433-6.

14. Kollner I, Sodeik B, Schreek S, Heyn H, von Neuhoff N, Germeshausen M et al. Mutations in neutrophil elastase causing congenital neutropenia lead to cytoplasmic protein accumulation and induction of the unfolded protein response. Blood 2006;108:493-500.

15. Grenda DS, Murakami M, Ghatak J, Xia J, Boxer LA, Dale D et al. Mutations of the ELA2 gene found in patients with severe congenital neutropenia induce the unfolded protein response and cellular apoptosis. Blood 2007;110:4179-87.

16. Person RE, Li FQ, Duan Z, Benson KF, Wechsler J, Papadaki HA et al. Mutations in proto-oncogene GFl1 cause human neutropenia and target ELA2. Nat Genet 2003;34:308-12.

17. Klein C, Grudzien M, Appaswamy G, Germeshausen M, Sandrock I, Schäffer AA et al. HAX1 deficiency causes autosomal recessive severe congenital neutropenia (Kostmann disease). Nat Genet 2007;39:86-92. 
18. Boxer LA. Severe congenital neutropenia: genetics and pathogenesis. Trans Am Clin Climatol Assoc 2006;117:13-32.

19. Carlsson G, Van't Hooft I, Melin M, Entesarian M, Laurencikas E, Nennesmo I et al. Central nervous system involvement in severe congenital neutropenia: neurological and neuropsychological abnormalities associated with specific HAX1 mutations. J Intern Med 2008;264:388-400.

20. Bonilla MA, Gillio AP, Ruggeiro M, Kernan NA, Brochstein JA, Abboud M et al. Effects of recombinant human granulocyte colony-stimulating factor on neutropenia in patients with congenital agranulocytosis. $\mathrm{N}$ Engl J Med 1989;320:1574-80.

21. Bonilla MA, Dale D, Zeidler C, Last L, Reiter A, Ruggeiro M et al. Long-term safety of treatment with recombinant human granulocyte colony-stimulating factor (G-CSF) in patients with severe congenital neutropenias. $\mathrm{Br} \mathrm{J}$ Haematol 1994;88:723-30.

22. Colotta F, Re F, Polentarutti N, Sozzani S, Mantovani A. Modulation of granulocyte survival and programmed cell death by cytokines and bacterial products. Blood 1992;80:2012-20.

23. Brach MA, deVos S, Gruss HJ, Herrmann F. Prolongation of survival of human polymorphonuclear Neutrophils by granulocyte-macrophage colony- stimulating factor is caused by inhibition of programmed cell death. Blood 1992;80:2920-4.

24. Fukunaga R, Ishizaka-Ikeda E, Seta Y, Nagata S. Expression cloning of a receptor for murine granulocyte colony-stimulating factor. Cell 1990; 61:341-50.

25. Kyas U, Pietsch T, Welte K. Expression of receptors for granulocyte colonystimulating factor on neutrophils from patients with severe congenital neutropenia and cyclic neutropenia. Blood 1992;79:1144-7.

26. Germeshausen M, Ballmaier M, Welte K. Incidence of CSF3R mutations in severe congenital neutropenia and relevance for leukemogenesis: results of a long-term survey. Blood 2007;109:93-9.

27. Germeshausen M, Skokowa J, Ballmaier M, Zeidler C, Welte K. G-CSF receptor mutations in patients with congenital neutropenia. Curr Opin Hematol 2008;15:332-7.

28. Rosenberg PS, Alter BP, Bolyard AA, Bonilla MA, Boxer LA, Cham B. The incidence of leukemia and mortality from sepsis in patients with severe congenital neutropenia receiving long-term G-CSF therapy. Blood 2006; 107:4628-35. 